\title{
Effective prevention of pseudothrombocytopenia in feline blood samples with the prostaglandin $I_{2}$ analogue lloprost
}

Barbara Riond ${ }^{1 *}$, Andrea Katharina Waßmuth ${ }^{1}$, Sonja Hartnack ${ }^{2}$, Regina Hofmann-Lehmann ${ }^{1}$ and Hans Lutz ${ }^{1}$

\begin{abstract}
Background: In vitro platelet aggregation in feline blood samples is a well-known phenomenon in veterinary clinical laboratories resulting in high numbers of pseudothrombocytopenia. Several attempts have been made to prevent or dissolve platelet aggregates in feline blood samples and to increase the reliability of feline platelet counts. Prostaglandin $\mathrm{I}_{2}\left(\mathrm{PGI}_{2}\right)$ is the most powerful endogenous inhibitor of platelet aggregation but unstable. lloprost is a stable $\mathrm{PGI}_{2}$ analogue. The aims of the present study were (1) to evaluate the anti-aggregatory effect of lloprost on feline platelet counts and to determine a useful concentration to inhibit platelet aggregation in EDTA samples from clinically healthy cats, (2) to investigate the effect of lloprost on hematological blood parameters, and (3) to determine stability of Iloprost in K3-EDTA tubes for up to 16 weeks. From 20 clinically healthy cats blood was drawn from the jugular vein and immediately distributed in a $1.3 \mathrm{ml} \mathrm{K}$-EDTA tube, and two $1.3 \mathrm{ml} \mathrm{K}$-EDTA tubes containing $20 \mathrm{ng}$ and $200 \mathrm{ng}$ lloprost, respectively. A complete blood cell count was performed on the Sysmex XT-2000iV and the Mythic 18 on eight consecutive time points after collection. Blood smears were evaluated for the presence of PLT aggregates.

Results: In the absence of lloprost, pseudothrombocytopenia was observed in $50 \%$ of the investigated samples that led to significantly decreased optical PLT counts by a mean of $105 \times 10^{3} / \mu \mathrm{l}$, which could be prevented by the addition of $1 \mu \mathrm{L}$ (20 ng) lloprost leading to an increase in PLT counts by a mean of $108 \times 10^{3} / \mu \mathrm{l}$.

Conclusion: This is the first study showing an anti-aggregatory effect of the $\mathrm{PG} \mathrm{I}_{2}$-analogue lloprost in feline EDTA blood. In all clinically healthy cats investigated, pseudothrombocytopenia was prevented by adding lloprost to EDTA tubes prior to blood collection. Furthermore, lloprost was very useful in preventing falsely increased WBC counts in samples with platelet aggregates analyzed on impedance-based hematological instruments. Iloprost is preferable to $\mathrm{PGI}_{2}$ or $\mathrm{PGE}_{1}$ due to its stability and easy and safe handling properties. Cytological evaluations of blood smears as well as other hematological parameters were not influenced to a clinically significant degree by the presence of lloprost.
\end{abstract}

Keywords: Feline EDTA blood, Iloprost, Platelets, Prostaglandin I2-analogue, Pseudothrombocytopenia, Platelet aggregates

\footnotetext{
* Correspondence: briond@vetclinics.uzh.ch

${ }^{1}$ Clinical Laboratory, Vetsuisse Faculty, University of Zurich, 8057 Zurich,

Switzerland

Full list of author information is available at the end of the article
}

\section{Biomed Central}

(c) 2015 Riond et al. Open Access This article is distributed under the terms of the Creative Commons Attribution 4.0 International License (http://creativecommons.org/licenses/by/4.0/), which permits unrestricted use, distribution, and reproduction in any medium, provided you give appropriate credit to the original author(s) and the source, provide a link to the Creative Commons license, and indicate if changes were made. The Creative Commons Public Domain Dedication waiver (http://creativecommons.org/publicdomain/zero/1.0/) applies to the data made available in this article, unless otherwise stated. 


\section{Background}

In vitro platelet aggregation in feline blood samples is a well-known phenomenon resulting in pseudothrombocytopenia, with reported prevalences of $52 \%$ [1], $62 \%$ [2], and $71 \%$ [3]. Several attempts have been made to prevent or dissolve platelet aggregates and decrease pseudothrombocytopenia in feline blood samples to increase the reliability of feline platelet counts. It has been shown that a citrate-based anticoagulant containing the platelet inhibitors theophylline, adenosine, and dipyridamole reduces feline platelet aggregation in blood samples more effectively than citrate or ethylenediaminetetraacetic acid (EDTA) [3]. Tvedten and Korcal investigated whether mixing blood with a vortex mixer could disaggregate platelet aggregates mechanically, but few of the investigated samples appeared to have all platelet aggregates dispersed [4]. Consequently vortex mixing does not seem to be a consistent means of correcting the problem of feline platelet aggregation. Prostaglandins are synthesized from arachidonic acid by cyclooxygenase in the cell membranes of nearly all tissues. Both prostaglandin $\mathrm{E}_{1}\left(\mathrm{PGE}_{1}\right)$ and prostaglandin $\mathrm{I}_{2}\left(\mathrm{PGI}_{2}\right)$ have platelet aggregation inhibitory activities, and $\mathrm{PGE}_{1}$ has been successfully used to inhibit platelet aggregates in platelet-rich feline plasma [5]. A combination of an optical platelet count together with adding $\mathrm{PGE}_{1}$ to EDTA blood collection tubes is recommended for platelet counting in feline patients with potential thrombocytopenia [6]. $\mathrm{PGI}_{2}$ is the most potent platelet aggregation inhibitor, but it is very unstable at physiological $\mathrm{pH}$ values and requires strict handling procedures [5]. Three decades ago, the stable $\mathrm{PGI}_{2}$ analogue Iloprost was synthesized. Iloprost is used as a therapeutic agent in human medicine to treat peripheral vascular diseases, severe pulmonary hypertension, and thrombangiitis obliterans [7]. Platelet aggregation and release reactions stimulated by aggregating agents such as arachidonic acid, collagen, or epinephrine are essentially abolished by nanomolar concentrations of Iloprost. The anti-aggregatory effect of Iloprost is based on an increase in cyclic adenosine monophosphate (cAMP) within the platelet. Platelets have high-affinity binding sites for $\mathrm{PGI}_{2}$ that can also bind Iloprost in a reversible, saturable manner. The formation of cAMP by the enzyme adenylate cyclase is mediated via these receptors. Increasing levels of cAMP within the platelet influence several processes involved in platelet activation, including the regulation of phospholipases and free cytosolic calcium levels [7]. Because of its chemical and biological stability, universal potent anti-aggregatory effect, and availability, Iloprost is more likely than $\mathrm{PGI}_{2}$ and $\mathrm{PGE}_{1}$ to be useful in preventing platelet aggregation in feline blood samples. The aims of the present study were (1) to evaluate the anti-aggregatory effect of Iloprost on feline platelet counts and to determine a useful concentration to inhibit platelet aggregation in EDTA samples from clinically healthy cats, (2) to investigate the effect of Iloprost on hematological blood parameters, and (3) to determine stability of Iloprost in $\mathrm{K}_{3}$-EDTA tubes.

\section{Methods}

\section{Pilot study with different lloprost concentrations}

To test the overall effectiveness of Iloprost to prevent feline platelet aggregation, six different Iloprost amounts between $1 \mu \mathrm{g}$ (50 $\mu \mathrm{L}$ of Ilomedin, Schering) and $20 \mathrm{ng}$ ( $1 \mu \mathrm{L}$ of Ilomedin) were tested in blood samples from five clinically healthy cats well known to build platelet aggregates in EDTA blood tubes (TVB 99/2007, 100/ 2007 , and 101/2007 approved by the veterinary office of the canton Zurich). Just before blood collection, a $1 \mathrm{~mL}$ ampulla containing $20 \mu \mathrm{g}$ of Iloprost (Ilomedin) was opened and a predetermined volume was pipetted into $1.3 \mathrm{~mL} \mathrm{~K}$-EDTA tubes (Sarstedt) with a micropipette (Calibra digital, Socorex Isba S.A.). Blood was collected with a needle (22 G, Neolus Terumo) and a $5 \mathrm{~mL}$ syringe (Omnifix, B. Braun) from the jugular vein. The needle was immediately removed after collection, and equal amounts of blood were placed in a $K_{3}$-EDTA tube and three $\mathrm{K}_{3}$-EDTA tubes containing different Iloprost concentrations. The two persons involved in the blood collection process ensured that filling, closing, and mixing of all blood tubes occurred nearly simultaneously. All tubes were gently mixed for $2 \mathrm{~min}$. A second blood collection was performed to test the remaining three Iloprost concentrations. For three of the five cats, blood collection was performed under deep sedation $(10 \mathrm{mg} / \mathrm{kg}$ ketamine, Narketan, Vétoquinol AG in combination with $0.1 \mathrm{mg} / \mathrm{kg}$ midazolam, Dormicum, Roche Pharma AG).

The blood samples were analyzed at $15 \mathrm{~min}(\mathrm{~min})$, $30 \mathrm{~min}$, and 1, 2, 3, and $4 \mathrm{~h}$ (h) after blood collection. Between time points, the blood was mixed at room temperature on an automated mixer (Rock ' $\mathrm{n}$ Roller 34201, Snijders Scientific B.V., AR). At each time point, blood samples were analyzed on the Sysmex XT2000iV (Sysmex Corporation) for impedance and optical platelet counts and for total white blood cell (WBC) counts [8], and a blood smear was prepared and stained (HemaTek, Siemens).

Approval for collecting blood samples was given by the veterinary office of the canton Zurich, Switzerland (TVB number 99/2007, 100/2007, and 101/2007).

\section{Evaluation of the effect of $20 \mathrm{ng}(1 \mu \mathrm{L})$ and $200 \mathrm{ng}$ $(10 \mu \mathrm{L})$ of lloprost on 20 feline EDTA samples}

Blood samples were next obtained from the jugular vein of 20 clinically healthy cats (TVB 99/2007, 100/2007, and 101/2007). Blood collection was performed as described for the pilot study. Immediately after collection, 
the needle was removed and equal amounts of blood were placed in $1.3 \mathrm{~mL} \mathrm{~K}_{3}$-EDTA tubes without Iloprost, with $1 \mu \mathrm{L}(20 \mathrm{ng})$ Iloprost, and with $10 \mu \mathrm{L}$ (200 ng) Iloprost, respectively. Blood collection was performed under deep sedation in 10 of the 20 cats. The blood samples were analyzed at $15 \mathrm{~min}$ and $1,2,3,4,6,8$, and $24 \mathrm{~h}$ after blood collection. Between time points, the blood was mixed on an automated mixer at room temperature (Rock 'n Roller 34201, Snijders Scientific B.V). At each time point, the blood samples were analyzed on the Sysmex XT-2000iV (Sysmex Corporation) for a complete blood cell count including impedance and optical platelet counts, and a blood smear was prepared. Seven cats with platelet aggregates were additionally analyzed on the Mythic 18 instrument (Orphée SA) for total WBC counts at two time points [9]. The first measurement was immediately after blood collection, and the second was performed when platelet counts on the Sysmex XT-2000iV dropped under the lower reference limit $\left(180 \times 10^{3} / \mu \mathrm{L}\right)$ for the first time. All blood smears were assessed by one of the authors for the presence of platelet aggregates by applying the following scoring system per slide: 0 , no aggregates; 1 , aggregates of 2-5 platelets; 2 , aggregates of $6-15$ platelets; 3 , aggregates of 16-50 platelets; and 4, aggregates of $>50$ platelets. Furthermore, blood smears were evaluated for estimation of WBC counts and to determine whether Iloprost has an effect of WBC and RBC morphology.

\section{lloprost stability study}

Iloprost stability was investigated over 16 weeks using blood samples from two clinically healthy cats known to develop platelet aggregates after each blood collection. Both cats had previously been used in the second experiment of the present study. Before study onset, 40 EDTA tubes (Sarstedt, $1.3 \mathrm{~mL}$ ) were prepared with $1 \mu \mathrm{L}$ (20 ng) of Ilomedin. Twenty tubes were stored at room temperature, and another 20 tubes were stored at $37^{\circ} \mathrm{C}$ in an incubator. Blood collection was performed after $1,2,3,6,8,12$, and 16 weeks of storage. At each time point, $3 \mathrm{~mL}$ of blood was collected from the jugular vein as previously described and distributed equally into one $\mathrm{K}_{3}$-EDTA tube, one $\mathrm{K}_{3}$-EDTA tube with $1 \mu \mathrm{L}$ (20 ng) Iloprost stored at room temperature, and one $\mathrm{K}_{3}$-EDTA tube with $1 \mu \mathrm{L}(20 \mathrm{ng})$ Iloprost stored at $37{ }^{\circ} \mathrm{C}$. The blood samples were analyzed $1,2,3$, and $4 \mathrm{~h}$ after collection in the Sysmex XT-2000iV for optical platelet counts.

\section{Statistical analysis}

Statistical analysis was performed with the software packages $\mathrm{R}$ and nlme [10]. Linear mixed effects models were used to model the outcome variable platelet counts, WBC, red blood cell (RBC), hematocrit (HCT), hemoglobin concentration (HGB), mean corpuscular hemoglobin $(\mathrm{MCH})$, mean corpuscular volume (MCV), and mean corpuscular hemoglobin concentration (MCHC) measured on the Sysmex XT-2000iV, with the potential explanatory variables time, Iloprost administration (yes or no), aggregates (no: scoring index blood smear evaluation 0,1 ; or yes: $2,3,4$ ), an interaction term between Iloprost and aggregates as fixed effects, and cats as random effects to account for potential withinanimal clustering. Model selection and validation were based on Akaike's Information Criterion and the residuals for normality and homogeneity were checked visually. The results of the linear mixed effects models are given as effect sizes and their corresponding standard errors and $p$-values. To evaluate the changes in WBC counts analyzed with the Mythic 18 instrument (Orphée $\mathrm{SA}$ ) at two time points, paired t-tests with and without Iloprost administration were performed.

Bar charts were made using GraphPad Prism (version 3.00 for Windows, GraphPad Software).

\section{Results}

Pilot study with different lloprost concentrations

Within $4 \mathrm{~h}$, mean platelet counts decreased in all EDTA tubes without Iloprost at timepoints $1 \mathrm{~h}, 2 \mathrm{~h}$, $3 \mathrm{~h}$ and $4 \mathrm{~h}$ under the lower reference limit $\left(180 \times 10^{3} /\right.$ $\mu \mathrm{L})$. In the EDTA tubes with Iloprost, mean platelet counts remained within the reference limits at each of the six tested Iloprost concentrations (Fig. 1). All tested Iloprost concentrations were effective to prevent pseudothrombocytopenia.

\section{Evaluation of the effect of $1 \mu \mathrm{L}(20 \mathrm{ng})$ and $10 \mu \mathrm{L}$ $(200 \mathrm{ng})$ Iloprost on 20 feline EDTA samples}

Fifty percent of the investigated feline EDTA samples without Iloprost showed pseudothrombocytopenia, with platelet counts under the lower reference limit at different time points. In EDTA tubes with Iloprost, pseudothrombocytopenia was prevented in all cases; however platelet aggregates were not completely dissolved. Blood smear evaluation of EDTA samples with Iloprost yielded platelet aggregation scores ranging from 0 to 2, whereas blood smears from EDTA samples without Iloprost had platelet aggregations scores ranging from 0 to 4 . Iloprost had no effect on WBC and RBC morphology.

The raw data of platelet counts measured by optical and impedance-based methods per time point, in the absence or presence of platelet aggregates and Iloprost administration are shown in Tables 1 and 2. The results of the linear mixed effects approach to assess potential effects of Iloprost, presence of aggregates, and an interaction between Iloprost and presence of aggregates as well as time on the optical and impedance-based platelet counts are shown in Table 3. In both methods, the 


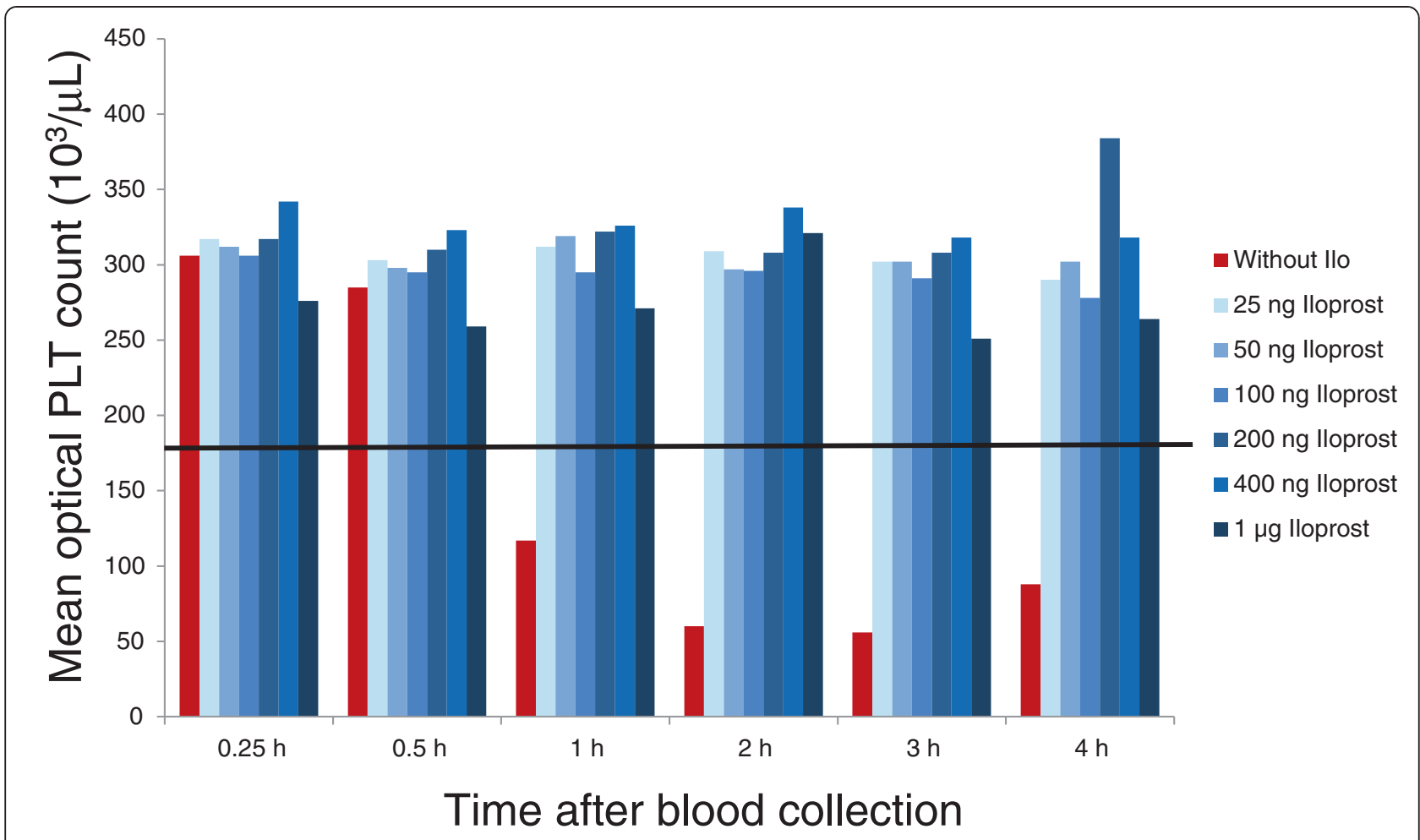

Fig. 1 Bar chart showing results from the pilot study with different lloprost concentrations. Mean optical platelet counts $\left(10^{3} / \mu \mathrm{l}\right)$ from 5 cats with platelet aggregation without lloprost and with 25 ng, 50 ng, 100 ng, 200 ng, 400 ng and 1 mg lloprost at 0.25 h, 0.5 h, 1 h, 2 h, 3 h and 4 h after blood collection. The black line indicates the upper reference interval for feline platelets $\left(180 \times 10^{3} / \mu \mathrm{L}\right)$

optical and impedance-based platelet counts, the effect of Iloprost on increasing the platelet counts (by $108 \times$ $10^{3} / \mu \mathrm{L}$ and $95 \times 10^{3} / \mu \mathrm{L}$ ) is mainly seen if aggregates are present, thus outweighing the effect of aggregates in decreasing platelet counts $\left(-105 \times 10^{3} / \mu \mathrm{L}\right.$ and $-94 \times 10^{3} /$ $\mu \mathrm{L}$, respectively). This indicates an interaction effect between Iloprost administration and presence of aggregates, thus meaning that an effect of Iloprost on the
PLT counts is mainly seen in the presence of aggregates but not in the absence. The interaction effect between Iloprost and presence of aggregates for each method is shown in Fig. 2 and Fig. 3. Over time, a slight decrease in platelet counts was seen. A significant difference between $1 \mu \mathrm{L}(20 \mathrm{ng})$ and $10 \mu \mathrm{L}$ (200 ng) Iloprost could not be found for either the impedance platelet count or the optical platelet count in a subsequent analysis using

Table 1 Means and standard deviations of optical platelet counts per time point, in the absence or presence of aggregates with and without lloprost administration

\begin{tabular}{|c|c|c|c|c|c|c|c|c|c|c|c|c|c|c|c|c|c|c|}
\hline \multirow{4}{*}{$\begin{array}{l}\text { Time } \\
\text { in } \\
\text { hours }\end{array}$} & \multicolumn{9}{|c|}{ Aggregates present } & \multicolumn{9}{|c|}{ Aggregates absent } \\
\hline & \multicolumn{6}{|l|}{ Ilo yes } & \multirow{2}{*}{\multicolumn{3}{|c|}{ Ilo no }} & \multicolumn{6}{|l|}{ llo yes } & \multirow{2}{*}{\multicolumn{3}{|c|}{ Ilo no }} \\
\hline & \multicolumn{3}{|l|}{$20 \mathrm{ng}$} & \multicolumn{3}{|l|}{$200 \mathrm{ng}$} & & & & \multicolumn{3}{|l|}{$20 \mathrm{ng}$} & \multicolumn{3}{|l|}{$200 \mathrm{ng}$} & & & \\
\hline & mean $^{1}$ & $s d^{1}$ & $\bar{n}$ & mean $^{1}$ & $s d^{1}$ & $\bar{n}$ & mean $^{1}$ & $s d^{1}$ & $n$ & mean $^{1}$ & $s d^{1}$ & $\bar{n}$ & mean $^{1}$ & $s d^{1}$ & $\bar{n}$ & mean $^{1}$ & $s d^{1}$ & $\bar{n}$ \\
\hline 0.15 & 296 & 42 & 4 & 296 & 37 & 4 & 288 & 127 & 5 & 343 & 124 & 16 & 340 & 129 & 16 & 338 & 125 & 15 \\
\hline 1 & 314 & 41 & 3 & 296 & 53 & 4 & 183 & 138 & 8 & 339 & 119 & 17 & 337 & 126 & 16 & 363 & 125 & 12 \\
\hline 2 & 285 & 15 & 2 & 275 & 37 & 2 & 81 & 70 & 10 & 342 & 119 & 18 & 337 & 124 & 18 & 365 & 131 & 10 \\
\hline 3 & 351 & 70 & 3 & 284 & $N A^{2}$ & 1 & 148 & 105 & 14 & 330 & 123 & 17 & 329 & 119 & 19 & 396 & 161 & 6 \\
\hline 4 & 276 & 29 & 3 & 304 & 67 & 5 & 179 & 88 & 13 & 334 & 122 & 17 & 331 & 132 & 15 & 369 & 173 & 7 \\
\hline 6 & 290 & 24 & 3 & 276 & 1 & 2 & 207 & 74 & 12 & 316 & 125 & 17 & 314 & 123 & 18 & 332 & 159 & 8 \\
\hline 8 & 239 & $N A^{2}$ & 1 & 330 & 88 & 2 & 205 & 72 & 11 & 287 & 128 & 19 & 286 & 127 & 18 & 309 & 154 & 9 \\
\hline 24 & 231 & $N A^{2}$ & 1 & 153 & $N A^{2}$ & 1 & 182 & 80 & 8 & 230 & 115 & 19 & 230 & 114 & 19 & 274 & 118 & 12 \\
\hline
\end{tabular}

${ }^{1}$ mean and standard deviation of platelet counts in $10^{3} \times \mu \mathrm{L}$ 
Table 2 Means and standard deviations of impedance-based platelet counts per time point, in the absence or presence of aggregates with and without lloprost administration

\begin{tabular}{|c|c|c|c|c|c|c|c|c|c|c|c|c|c|c|c|c|c|c|}
\hline \multirow{4}{*}{$\begin{array}{l}\text { Time } \\
\text { in hours }\end{array}$} & \multicolumn{9}{|c|}{ Aggregates present } & \multicolumn{9}{|c|}{ Aggregates absent } \\
\hline & \multicolumn{6}{|c|}{ lloprost yes } & \multirow{2}{*}{\multicolumn{3}{|c|}{ Iloprost no }} & \multicolumn{6}{|c|}{ lloprost yes } & \multirow{2}{*}{\multicolumn{3}{|c|}{ Iloprost no }} \\
\hline & \multicolumn{3}{|l|}{$20 \mathrm{ng}$} & \multicolumn{3}{|l|}{$200 \mathrm{ng}$} & & & & \multicolumn{3}{|l|}{$20 \mathrm{ng}$} & \multicolumn{3}{|l|}{$200 \mathrm{ng}$} & & & \\
\hline & mean $^{1}$ & $s d^{1}$ & $\bar{n}$ & mean $^{1}$ & $s d^{1}$ & $\bar{n}$ & mean $^{1}$ & $\mathrm{sd}^{1}$ & $n$ & mean $^{1}$ & $s d^{1}$ & $\frac{\mathrm{n}}{\mathrm{n}}$ & mean $^{1}$ & $s d^{1}$ & $\mathrm{n}$ & mean $^{1}$ & $s d^{1}$ & $\bar{n}$ \\
\hline 0.15 & 266 & 85 & 4 & 278 & 68 & 4 & 276 & 148 & 5 & 310 & 104 & 16 & 300 & 120 & 16 & 295 & 95 & 15 \\
\hline 1 & 281 & 85 & 3 & 257 & 83 & 4 & 171 & 134 & 8 & 295 & 112 & 17 & 295 & 109 & 16 & 294 & 99 & 12 \\
\hline 2 & 142 & 81 & 2 & 192 & 22 & 2 & 66 & 57 & 10 & 271 & 111 & 18 & 258 & 113 & 18 & 288 & 113 & 10 \\
\hline 3 & 282 & 136 & 3 & 154 & $N A^{2}$ & 1 & 136 & 100 & 14 & 234 & 100 & 17 & 246 & 120 & 19 & 280 & 80 & 6 \\
\hline 4 & 176 & 45 & 3 & 249 & 119 & 5 & 168 & 83 & 13 & 238 & 118 & 17 & 236 & 111 & 15 & 252 & 112 & 7 \\
\hline 6 & 175 & 21 & 3 & 186 & 1.4 & 2 & 187 & 84 & 12 & 215 & 113 & 17 & 215 & 115 & 18 & 237 & 108 & 8 \\
\hline 8 & 150 & $N A^{2}$ & 1 & 303 & 165 & 2 & 181 & 90 & 11 & 191 & 97 & 19 & 188 & 90 & 18 & 237 & 81 & 9 \\
\hline 24 & 140 & $N A^{2}$ & 1 & 83 & $N A^{2}$ & 1 & 152 & 79 & 8 & 137 & 61 & 19 & 141 & 70 & 19 & 202 & 78 & 12 \\
\hline
\end{tabular}

${ }^{1}$ mean and standard deviation of platelet counts in $10^{3} \times \mu \mathrm{L}$

21 cat

a linear mixed effects models to compare the effect of different amounts of Iloprost (Sysmex, $P=0.25$; Mythic, $P=0.83$ ).

No significant effect of Iloprost administration on WBC, RBC, HGB, HCT or MCV was found. Although significant ( $p$-values of 0.0012 and 0.004), the effect of Iloprost administration on $\mathrm{MCH}$ and $\mathrm{MCHC}$ was considered to be clinically irrelevant with a decrease of $0.052 \mathrm{pg}( \pm 0.016 \mathrm{pg})$ and $-0.12 \mathrm{~g} / \mathrm{dL}( \pm 0.04 \mathrm{~g} / \mathrm{dL})$. A significant increase over time for $\mathrm{MCV}, \mathrm{RBC}, \mathrm{HCT}$, $\mathrm{HGB}$ and $\mathrm{MCHC}$, albeit clinically not relevant, was observed.

In EDTA samples without Iloprost, mean WBC counts measured with the Mythic 18 increased strongly at the second measurement time point compared with the first. At the first time point mean WBC count was $8.87 \times 10^{3}$ / $\mu \mathrm{L}\left( \pm 2.50 \times 10^{3} / \mu \mathrm{L}\right)$, and at the second time point it was $15.49 \times 10^{3} / \mu \mathrm{L}\left( \pm 3.07 \times 10^{3} / \mu \mathrm{L} 3.07\right)$. In contrast mean WBC counts in EDTA tubes with Iloprost remained completely stable at $8.66 \times 10^{3} / \mu \mathrm{L}\left( \pm 2.24 \times 10^{3} / \mu \mathrm{L}, \pm\right.$ $\left.2.21 \times 10^{3} / \mu \mathrm{L}\right)$ at both time points. Based on paired $\mathrm{t}$ - tests, the difference between the two time points differed significantly in the samples without Iloprost $(p<0.0001)$ but not in the group with Iloprost administration. Blood smear evaluation from EDTA samples without Iloprost showed platelet aggregates in all cats at the second measurement time point; however no change in WBC count and distribution was observed compared to the blood smears from EDTA samples with Iloprost.

\section{Iloprost stability study}

Results of the Iloprost stability experiment are displayed in Table 4. Optical platelet counts in EDTA tubes containing Iloprost at room temperature or in the incubator were higher than mean platelet counts in EDTA tubes without Iloprost. Mean platelet counts in EDTA tubes without Iloprost were below the lower reference limit at time point $2 \mathrm{~h}$.

\section{Discussion}

This is the first study showing a strong anti-aggregatory effect for the synthetic $\mathrm{PGI}_{2}$ analogue Iloprost on feline

Table 3 Statistical analysis of optical platelet and impedance platelet counts

\begin{tabular}{|c|c|c|c|c|c|c|}
\hline & \multicolumn{2}{|c|}{ Value $\left(10^{3} / \mu \mathrm{L}\right)$} & \multicolumn{2}{|c|}{$\operatorname{SE}\left(10^{3} / \mu \mathrm{L}\right)$} & \multicolumn{2}{|l|}{$P$-value } \\
\hline & Optical & Impedance & Optical & Impedance & Optical & Impedance \\
\hline constant & 332.3 & 287.9 & 25.5 & 21.0 & $<0.0001$ & $<0.001$ \\
\hline \|lo & -0.4 & -25.8 & 6 & 7.1 & 0.9428 & 0.0003 \\
\hline Aggregates & -105.4 & -94.4 & 8.1 & 9.6 & $<0.0001$ & $<0.001$ \\
\hline Time & -3.7 & -4.9 & 0.3 & 0.3 & $<0.0001$ & $<0.001$ \\
\hline Interaction Ilo:Aggregates & 108 & 95.3 & 11.3 & 13.5 & $<0.0001$ & $<0.001$ \\
\hline
\end{tabular}

This table presents the results of a linear mixed effects model with PLT counts as outcome variable. The following variables were included as explanatory variables in the final model: administration of lloprost ("Ilo"), presence or absence of aggregates ("Aggregates"), measurements taken over time ("Time") as well as an interaction effect between lloprost and presence of aggregates ("Interaction Test llo:Aggregates"). The results are given in the form of the mean effect size ("Value") and their corresponding standard error ("SE") as a measure of uncertainty and the p-values of each explanatory variable. The constant term or intercept indicates the value at which the fitted regression line crosses the $y$-axis or in other words corresponds to the mean PLT count if there would be no lloprost administration, and no aggregates present at time point 0 


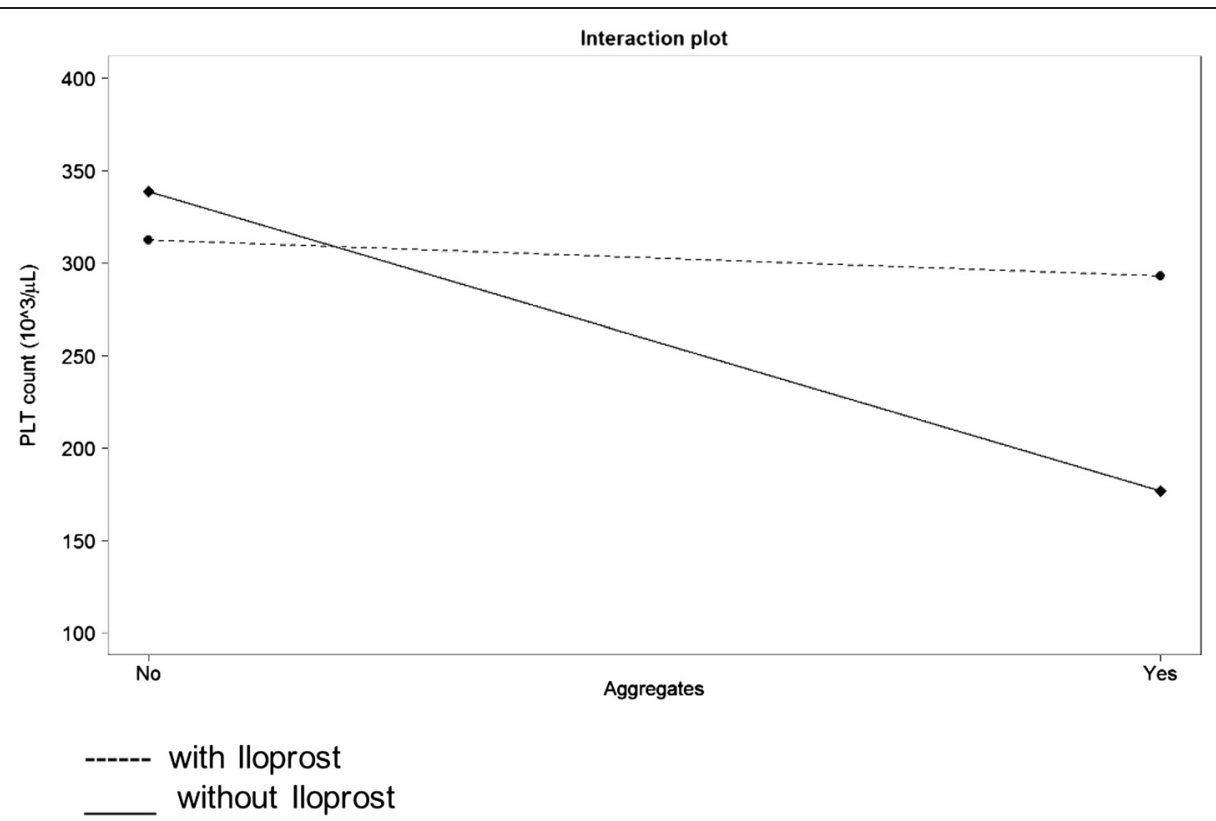

Fig. 2 Interaction plot for optical platelet (platelet) counts in cats with (Yes) and without (No) platelet (platelet) aggregates. The black dashed line corresponds to lloprost (Yes)

platelet counts. In clinically healthy cats, pseudothrombocytopenia was completely prevented in all blood samples in EDTA tubes containing Iloprost. Without Iloprost, if significant numbers of platelet aggregates were present (score of $>1$ ) in an EDTA blood sample, the mean optical platelet count decreased by $105 \times 10^{3} / \mu \mathrm{L}$. This decrease was completely counterbalanced by the presence of Iloprost in the EDTA tube. Iloprost did not affect optical platelet counts in samples without aggregates or with score 1 aggregates. For impedance platelet counts, the effect of Iloprost on aggregates was similar.

Iloprost effectively prevented pseudothrombocytopenia in the present study, but it did not dissolve platelet aggregates completely. Cats with optical platelet counts that remained within the reference intervals during the evaluation period nevertheless showed occasionally small

Interaction plot

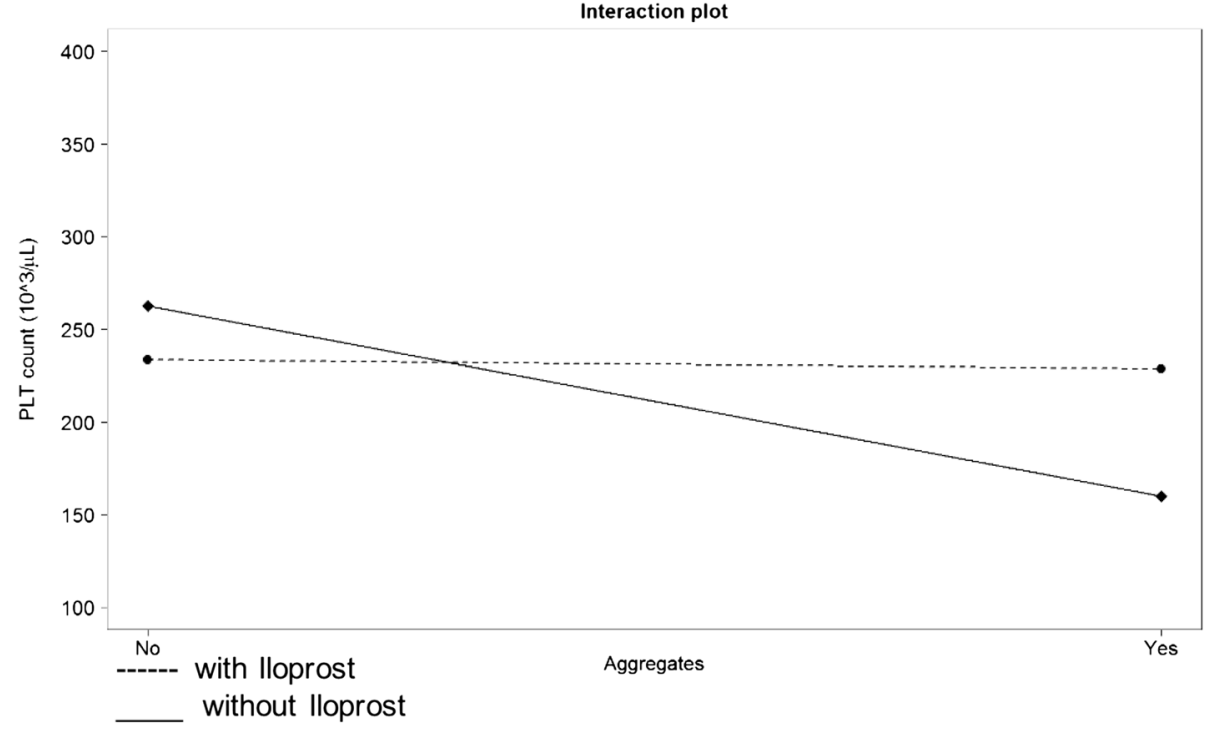

Fig. 3 Interaction plot for impedance platelet (platelet) counts in cats with (Yes) and without (No) platelet (platelet) aggregates. The black dashed line corresponds to lloprost (Yes) 
Table 4 Results of the stability study (measuring time point 2 h) for cat 1 and cat 2: Platelet counts in the EDTA tube, the EDTA tube +20 ng lloprost stored at room temperature and the EDTA tube +20 ng lloprost stored at $37^{\circ} \mathrm{C}$

\begin{tabular}{|c|c|c|c|c|c|c|}
\hline \multirow[t]{2}{*}{$\begin{array}{l}\text { Optical platelet } \\
\text { counts }\left(10^{3} / \mu \mathrm{L}\right)\end{array}$} & \multicolumn{2}{|l|}{ EDTA } & \multicolumn{2}{|c|}{$\begin{array}{l}\text { EDTA + } 20 \text { ng } \\
\text { Iloprost stored } \\
\text { at room } \\
\text { temperature }\end{array}$} & \multicolumn{2}{|c|}{$\begin{array}{l}\text { EDTA + } 20 \mathrm{ng} \\
\text { lloprost stored } \\
\text { at } 37^{\circ} \mathrm{C}\end{array}$} \\
\hline & cat 1 & cat 2 & cat 1 & cat 2 & cat 1 & cat 2 \\
\hline Week 1 & 29 & 91 & 292 & 480 & 296 & 461 \\
\hline Week 2 & 25 & 22 & 324 & 463 & 280 & 456 \\
\hline Week 3 & 11 & 77 & 323 & 528 & 323 & 535 \\
\hline Week 6 & 17 & 30 & 358 & 476 & 394 & 477 \\
\hline Week 8 & 16 & 21 & 296 & 462 & 313 & 478 \\
\hline Week 12 & 33 & 20 & 339 & 448 & 372 & 461 \\
\hline Week 16 & 16 & 20 & 288 & 370 & 299 & 395 \\
\hline
\end{tabular}

platelet aggregates in blood smears, which were classified according to the scoring index as 1 or 2 . In blood smears from EDTA samples with Iloprost, these platelets were observed to retain their granules over the evaluation period, and appeared morphologically round. In contrast, platelets that formed aggregates in samples without Iloprost lost their shape, formed pseudopods, and lost their granules. The scoring index used in this study to judge the presence of platelet aggregates in the blood smear was limited in that only the size, but not the frequency of aggregates, was investigated. If a single platelet aggregate with a score of 2 (6-15 platelets) was identified, the sample was categorized as having a platelet aggregate score of 2 . In feline samples with unaffected optical platelet counts, platelet aggregates consisted mainly of only six to seven platelets. The blood smear evaluation technique used in this study seemed to be a very sensitive method for detecting platelet aggregates, particularly if the feathered edges of the smear were examined. From this observation it can be speculated that a few platelet aggregates consisting only of a small number of platelets do not influence the optical platelet count of the Sysmex XT-2000iV.

Similar to $\mathrm{PGI}_{2}, \mathrm{PGE}_{1}$ has platelet anti-aggregatory properties [5] previously showed that feline platelets exposed to $\mathrm{PGE}_{1}$ become immediately and persistently nonreactive to agonists, which prevents platelet aggregation and consequently improves platelet count accuracy. Tvedten and Johansson [6] demonstrated higher feline platelet counts in feline samples containing $\mathrm{PGE}_{1}$, although a complete inhibition of aggregation could not be achieved. On blood smear evaluation, $\mathrm{PGE}_{1}$-treated samples had occasional platelet aggregates, but many more and larger aggregates were seen in EDTA samples. Although $\mathrm{PGE}_{1}$ has been shown to successfully prevent in vitro platelet aggregation in blood samples from cats, it is not used in daily laboratory hematology testing because of its poor stability.

In vivo, $\mathrm{PGI}_{2}$ is one of the main platelet anti-aggregatory agents. Similar to $\mathrm{PGE}_{1}, \mathrm{PGI}_{2}$ is characterized by poor stability; it has a half-life of approximately $2 \mathrm{~min}$ at $37{ }^{\circ} \mathrm{C}$ and $\mathrm{pH}$ of 7.4 , and its activity is gone in $20 \mathrm{~min}$ at $22^{\circ} \mathrm{C}$ [11]. Use of $\mathrm{PGI}_{2}$ in laboratory hematology testing is not practical. The synthetic $\mathrm{PGI}_{2}$ analogue Iloprost is both qualitatively and quantitatively more effective as an inhibitor of platelet aggregation than either $\mathrm{PGI}_{2}$ or $\mathrm{PGE}_{1}$ [7]. Furthermore, Iloprost is available as Ilomedin, an intravenous drug in human medicine. Ilomedin is readily usable due to its pharmacological formulation. In the present study, all Iloprost concentrations tested showed the same strong anti-aggregatory effect on feline platelets. Concentrations for $\mathrm{PGI}_{2}$ causing $50 \%$ inhibition of ADPinduced platelet aggregation have been reported for different species other than the cat, and range from 0.5 to $3.7 \mathrm{ng} / \mathrm{mL}$ [11]. Due to the specific peculiarities of the feline platelet, which appears to be more readily activated and aggregated compared to other species [12], the authors assumed that higher amounts of Iloprost would be needed to inhibit aggregation of feline platelets. To investigate the effect of Iloprost in a reasonable number of cat blood samples, $1 \mu \mathrm{L}(20 \mathrm{ng})$ and $10 \mu \mathrm{L}(200 \mathrm{ng})$ of Iloprost were chosen. Both amounts achieved the same effect, and no significant difference between EDTA tubes with $1 \mu \mathrm{L}$ vs. $10 \mu \mathrm{L}$ was observed. For this reason, the Iloprost stability study and Iloprost testing in clinical cases were performed with $1 \mu \mathrm{L}$ (20 ng) Iloprost. The smaller amounts are likely sufficient to prevent pseudothrombocytopenia, but amounts greater than $1 \mu \mathrm{L}(20 \mathrm{ng})$ and $10 \mu \mathrm{L}$ (200 ng) would be needed to completely prevent platelet aggregation.

The use of Iloprost in veterinary hematology would be beneficial for preventing pseudothrombocytopenia in feline EDTA samples. Adding Iloprost to EDTA tubes used for hematological analysis of feline blood samples should improve the reliability of platelet counts. The main weaknesses of $\mathrm{PGI}_{2}$ and $\mathrm{PGE}_{1}$ for routine application are their poor stability and complex handling procedures. In contrast, Iloprost can be stored at room temperature, and is easy to handle and immediately useable. In the present study Iloprost was stored for up to 16 weeks in EDTA tubes at room temperature and at $37{ }^{\circ} \mathrm{C}$. The effectiveness of Iloprost on platelet aggregates persisted over the entire storage time. Iloprost did not significantly affect hematological parameters, cytological evaluation of the blood smears and the observed decreases in $\mathrm{MCH}$ and $\mathrm{MCHC}$ were negligible.

It is a well-known phenomenon in feline blood samples that platelet aggregates can falsely increase WBC counts and decrease platelet counts in impedance-based 
hematological instruments $[13,14]$. In the present study, false-positive leucocytosis was observed in six out of seven EDTA samples, whereas false leucocytosis did not occur in the EDTA samples with Iloprost. This observation is important because impedance-based instruments are widely used in veterinary practices, and false WBC counts due to platelet aggregation are a common finding. Using EDTA tubes with Iloprost for hematological analysis on impedance instruments would improve the reliability of both WBC counts and platelet counts in cats.

\section{Conclusions}

In conclusion, this is the first study showing an antiaggregatory effect of the $\mathrm{PGI}_{2}$-analogue Iloprost in feline EDTA blood. In all clinically healthy cats investigated, pseudothrombocytopenia was prevented by adding Iloprost to EDTA tubes prior to blood collection. Furthermore, Iloprost was very useful in preventing falsely increased WBC counts in samples with platelet aggregates analyzed on impedance-based hematological instruments. Iloprost is preferable to $\mathrm{PGI}_{2}$ or $\mathrm{PGE}_{1}$ due to its stability and easy and safe handling properties. Cytological evaluations of blood smears as well as other hematological parameters were not influenced to a clinically significant degree by the presence of Iloprost.

\begin{abstract}
Abbreviations
PLT: Platelets; WBC: White blood cells; EDTA: Ethylenediaminetetraacetic acid; h: Hours; min: Minutes; PGE1: Prostaglandin E1; PGI2: Prostaglandin 12; CAMP: Cyclic adenosine monophosphate; HCT: Haematocrit; HGB: Hemoglobin concentration; $\mathrm{MCH}$ : Mean corpuscular hemoglobin; MCV: Mean corpuscular volume; MCHC: Mean corpuscular hemoglobin concentration.
\end{abstract}

\section{Competing interests}

The authors declare no competing interests.

\section{Authors' contribution}

$\mathrm{BR}, \mathrm{AKW}, \mathrm{RHL}, \mathrm{HL}$ designed the study, BR and AKW performed the experiments and wrote the paper, SH performed statistical analysis. All authors read and approved the final manuscript.

\section{Acknowledgement}

The authors express their gratitude to the animal caretakers and technicians of the Clinical Laboratory for helpful contribution and support and excellent laboratory assistance.

\section{Author details}

${ }^{1}$ Clinical Laboratory, Vetsuisse Faculty, University of Zurich, 8057 Zurich, Switzerland. 'Section of Epidemiology, Vetsuisse Faculty, University of Zurich, 8057 Zurich, Switzerland.

Received: 10 March 2015 Accepted: 28 July 2015

Published online: 06 August 2015

\section{References}

1. Moritz A, Hoffmann C. [Platelet count in the cat]. Tierärztliche Praxis Ausgabe K Kleintiere Heimtiere. 1997;25(6):695-700.

2. Zelmanovic D, Hetherington EJ. Automated analysis of feline platelets in whole blood, including platelet count, mean platelet volume, and activation state. Vet Clin Pathol. 1998:27(1):2-9.

3. Norman EJ, Barron RCJ, Nash AS, Clampitt RB. Evaluation of a citrate-based anticoagulant with platelet inhibitory activity for feline blood cell counts. Vet Clin Pathol. 2001;30(3):124-32.
4. Tvedten $\mathrm{H}$, Korcal D. Vortex mixing of feline blood to disaggregate platelet clumps. Vet Clin Pathol. 2001;30(3):104-6.

5. Welles EG, Bourne C, Tyler JW, Boudreaux MK. Detection of activated feline platelets in platelet-rich plasma by use of fluorescein-labeled antibodies and flow cytometry. Vet Pathol. 1994;31(5):553-60.

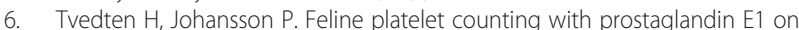
the Sysmex XT-2000iV. Vet Clin Pathol. 2010;39(2):190-2.

7. Grant SM, Goa KL. Iloprost. A review of its pharmacodynamic and pharmacokinetic properties, and therapeutic potential in peripheral vascular disease, myocardial ischaemia and extracorporeal circulation procedures. Drugs. 1992;43(6):889-924.

8. Weissenbacher S, Riond B, Hofmann-Lehmann R, Lutz H. Evaluation of a novel haematology analyser for use with feline blood. Vet J. 2011;187(3):381-7.

9. Wassmuth AK, Riond B, Hofmann-Lehmann R, Lutz H. Evaluation of the Mythic 18 hematology analyzer for use with canine, feline, and equine samples. J Vet Diagn Invest. 2011;3:436-53.

10. Pinheiro J, Bates D, DebRoy S, Sarkar D, and the R Core team: nlme: Linear and Nonlinear Mixed Effects Models. In., R package version 3.1-93 edn. R Foundation for statistical computing: Vienna; 2009.

11. Whittle BJ, Moncada S, Vane JR. Comparison of the effects of prostacyclin (PGI2), prostaglandin E1 and D2 on platelet aggregation in different species. Prostaglandins. 1978;16(3):373-88.

12. Russel KE: Platelet Kinetics and Laboratory Evaluation of Thrombocytopenia. In: Schalm's Veterinary Hematology. 6th edn. Edited by Weiss DJ, Wardrop KJ: Wiley-Blackwell: Ames, lowa; 2010: 576-585.

13. Norman EJ, Barron RCJ, Nash AS, Clampitt RB. Prevalence of low automated platelet counts in cats: Comparison with prevalence of thrombocytopenia based on blood smear estimation. Vet Clin Pathol. 2001;30(3):137-40.

14. Knoll JS, Rowell SL. Clinical hematology. In-clinic analysis, quality control, reference values, and system selection. Vet Clin North Am Small Anim Pract. 1996;26(5):981-1002.

\section{Submit your next manuscript to BioMed Central and take full advantage of:}

- Convenient online submission

- Thorough peer review

- No space constraints or color figure charges

- Immediate publication on acceptance

- Inclusion in PubMed, CAS, Scopus and Google Scholar

- Research which is freely available for redistribution 